\title{
MOBILIDADE COMO INDICADOR DA QUALIDADE DE VIDA URBANA
}

\section{MOBILITY AS AN INDICATOR OF URBAN QUALITY OF LIFE}

\author{
A. Paula Deluca de Moura \& B. Gisela Barcellos de Souza \\ Universidade Federal de Minas Gerais (UFMG), Brasil. \\ pauladeluccamoura@gmail.com \\ giselabarcellos@ufmg.br
}

\begin{abstract}
RESUMO
As cidades contemporâneas se caracterizam pela urbanização dispersa que torna as possibilidades alternativas de mobilidade em um forte elemento de exclusão social. Nesse sentido, a ampliação do acesso ao transporte coletivo afigura-se como uma política no sentido oposto; como indutora da qualidade de vida urbana. Corroboram para esta asseveração indicadores sociais que, a fim de mensurar a qualidade de vida em municípios brasileiros e auxiliar na proposição de políticas urbanas, incluem o transporte coletivo dentre seus dados de origem. $O$ presente artigo discorre sobre a mobilidade como elemento imbricado com a questão da acessibilidade e inclusão social e investiga como ela é medida em alguns dos índices de qualidade de vida municipais. Para tanto, serão comparados os indicadores utilizados em quatro municípios brasileiros.
\end{abstract}

Palavras-chave: mobilidade urbana, indicadores sociais, qualidade de vida urbana.

Linha de Investigação: 2: Cidade e Ambiente.

Tópico: Acessibilidade e mobilidade sustentável.

\begin{abstract}
Contemporary cities are characterized by dispersed urbanization that makes alternative possibilities of mobility in a strong element of social exclusion. In this sense, the expansion of access to public transport appears to be a policy in the opposite direction; as an inducer of urban quality of life. They corroborate social indicators that, in order to measure quality of life in Brazilian municipalities and assist in the proposition of urban policies, include public transport among their source data. This article discusses mobility as an element intertwined with the issue of accessibility and social inclusion and investigates how it is measured in some of the municipal quality of life indexes. To this end, the indicators used in four Brazilian municipalities will be compared.
\end{abstract}

Keywords: mobility, social indicators, urban quality of life.

Research line: 2: City and Environment.

Topic: Accessibility and sustainable mobility. 


\section{SÃOPAULO15 17 LISBOA $25 \sim 26$ JUN 2020}

\section{Introdução}

Como as pessoas se movem nas grandes cidades brasileiras? Como a mobilidade afeta a qualidade de vida dessas pessoas? Segundo dados da Pesquisa de Orçamento Familiares (POF) divulgada em 2019 pelo IBGE, naquele ano, pela primeira vez as despesas de consumo das famílias brasileiras com transporte ultrapassam os gastos com alimentação. Com cidades cada vez mais dispersas e segregadas, deslocamentos em grandes distâncias se tornaram indispensáveis para acessar os bens e serviços ofertados. $\mathrm{O}$ acesso e usufruto da cidade passou a estar imbricado nas ofertas e alternativas de mobilidade.

Tais questões merecem ser melhor debatidas e compreendidas face a conceitos seminais na teoria e prática do planejamento urbano. O Direito à Cidade se manifesta, segundo Lefèbvre (2001), como uma "forma superior dos direitos: direito à liberdade, à individualização na socialização, ao habitat e ao habitar". Ora, não é possível se ter liberdade e individualização na socialização, sem amplo acesso à mobilidade nas cidades contemporâneas.

Efetivamente, as implicações sociais e espaciais da mobilidade se intensificam no contexto da cidade contemporânea. Ao contrário das cidades compactas, nas cidades da urbanização difusa ampliam-se progressivamente as necessidades de deslocamentos e as demandas por uma infraestrutura viária mais robusta. Ademais, a produção do espaço sob a ótica do capital amplia a segregação socioespacial e a expansão das áreas periféricas se intensifica. Neste contexto, políticas de transporte que priorizam o automóvel particular consolidam a redução das possibilidades de acesso aos espaços públicos.

[...] hoje, mover-se tornou-se indispensável para acessar a maioria dos bens, dos serviços e das relações sociais [...] condiciona o acesso à habitação, ao trabalho, à educação, à cultura etc. [...] O direito à circulação tornou-se uma espécie de direito genérico, do qual derivam numerosos outros direitos [...] (ASCHER, 2004, grifo nosso).

A incorporação da noção de Direito à Cidade nos dispositivos legais pertinentes à política urbana no Brasil ainda que distante do conceito lefebvriano -, remonta ao final da década de 1980, com a formação do Movimento Nacional da Reforma Urbana (MNRU). A atuação deste movimento culminou na emenda popular pela reforma urbana na Constituição Federal de 1988 e, anos depois, na aprovação do Estatuto da Cidade em 2001 que incorpora a mobilidade ao definir o "direito às cidades sustentáveis" como "o direito à terra urbana, à moradia, ao saneamento ambiental, à infraestrutura urbana, ao transporte e aos serviços públicos, ao trabalho e ao lazer, para as presentes e futuras gerações" (BRASIL, 2001, grifo nosso).

Na década seguinte é instituída pela Lei no 12.587/2012 que trata da Política Nacional de Mobilidade Urbana (PNMU). Esta tem como um dos objetivos a redução das desigualdades e promoção da inclusão social, fato que aproxima a política de mobilidade da gestão democrática da cidade. A mobilidade passa a ser considerada elemento que contribui para a qualidade de vida urbana ao propiciar o acesso da população às oportunidades oferecidas pela cidade (BRASIL, 2012).

Dessa forma, o presente artigo tem como objetivo avaliar como as políticas urbanas municipais consideram a relação entre mobilidade e qualidade de vida. Para tanto, parte-se de uma breve revisão dos conceitos de mobilidade, acessibilidade e qualidade de vida urbana, para investigar e comparar quatro indicadores sociais: o Índice de Qualidade de Vida Urbana de Belo Horizonte (IQVU-BH), Índice de Qualidade de Vida de Curitiba (IQVC), Índice de Qualidade de Vida de Santo André (IQVSA), e Índice de Bem-Estar Urbano (IBEU). 


\section{XII $\mathbf{S}$ S ÃO PAULO15 17 LISBOA $25 \sim 26$ JUN 2020}

\section{Mobilidade, acessibilidade e qualidade de vida urbana}

Tratadas na língua corrente como sinônimos, acessibilidade e mobilidade não são intercambiáveis em termos técnicos. O engenheiro Cardoso (2008), conceitua a mobilidade como o número médio de viagens diárias, vinculadas a todos os modais, realizadas pelos habitantes de determinada área. Para este autor, a mobilidade da população deve ser calculada dividindo-se o total de viagens ${ }^{1}$ realizadas pelo habitante da área em estudo pelo número total de pessoas residentes nesta mesma localidade. No mesmo sentido, Araújo et al (2011) tratam a mobilidade como a facilidade de deslocamento das pessoas e bens na cidade e concluem que a mobilidade cresce acentuadamente com a renda.

Uma visão crítica ao conceito tradicional de mobilidade vinculado estritamente à oferta de meios de transporte é apresentada pelo engenheiro e sociólogo Vasconcellos (2001). Segundo o autor, um grande número de deslocamentos não representa necessariamente boas condições de vida, pois pode refletir a necessidade de viagens excessivas frente à precariedade do sistema de transportes. Para ele, a ampliação do conceito de mobilidade surge com o vínculo à acessibilidade, tida como a facilidade de chegar aos destinos e não apenas à facilidade de cruzar o espaço.

De forma similar, Santos (2005), em seu estudo sobre a qualidade no serviço de transporte público urbano, afirma que a acessibilidade se relaciona com as distâncias que os usuários caminham quando utilizam o transporte coletivo, da origem da viagem até o ponto de embarque e do ponto de desembarque até o destino final. Assim, o tempo de caminhada até o destino final e as condições de caminhabilidade afetam a qualidade dos deslocamentos individuais. Um modo diferente de abordar a acessibilidade é apresentado pela geógrafa Hanson (1995) que traz a acessibilidade como o número de oportunidades ou "lugares ativos" no território, fato que fundamenta sua visão de que a acessibilidade deveria ser o tópico central de uma medida de qualidade de vida.

Ora, se a mobilidade é proporcional à facilidade de deslocamento e a acessibilidade indica o número de oportunidades que a cidade oferece aos cidadãos, conclui-se que ambos se relacionam com a forma como o indivíduo interage com o espaço urbano.

A acessibilidade urbana é condicionada pela interação entre o uso do solo e transporte e se constitui como um importante indicador de exclusão social (...). Nesse sentido, a acessibilidade, ao ser parte integrante e fundamental da dinâmica e do funcionamento das cidades, passa a ser um elemento que contribui para a qualidade de vida urbana, na medida em que facilita o acesso da população aos serviços e bens urbanos, além de viabilizar sua aproximação com as atividades econômicas (Cardoso e Matos, 2007, p. 95).

Historicamente, o processo de produção espacial das cidades brasileiras é calcado, desde o período colonial, em ações de marginalização da população menos favorecida que promovem uma organização social desigual. Tal situação se agrava no contexto da cidade contemporânea com a ampliação das distâncias da vida cotidiana. A metropolis a la carte definida por Sieverts (2003), possui uma maior variedade de espaços e ações que somente são acessíveis por uma parcela limitada da população provida do automóvel individual.

\footnotetext{
1Viagem: movimento de uma pessoa entre dois pontos (origem e destino) com motivo definido e utilizando-se para isso, um ou mais modos de transporte (Metrô de São Paulo, 1997 apud Cardoso, 2008).
} 


\section{SÃOPAULO15 17 LISBOA $25 \sim 26$ JUN 2020}

Diante desse cenário segregacionista, a mensuração da qualidade de vida ganhou relevância no Brasil principalmente a partir da década de 90 . Seu marco inicial foi a concepção do Primeiro Relatório Internacional sobre o Desenvolvimento Humano pelo Programa das Nações Unidas para o Desenvolvimento em 1992, que apresenta o IDH - Índice de Desenvolvimento Humano - composto por indicadores de condições de saúde, de educação e renda da população.

A Organização Mundial de Saúde (OMS) conceitua a qualidade de vida como a percepção que o indivíduo tem de sua própria condição de vida, dentro do seu próprio contexto de cultura e sistema de valores, considerando seus objetivos de vida, as expectativas e as preocupações (OMS, 2002). Por outro lado, Nahas (2015), coordenadora do IQVU-BH, afirma que o acréscimo do termo "urbana" na expressão "qualidade de vida" mudou radicalmente seu sentido.

Saindo de um enfoque na pessoa, no indivíduo - para onde remete o conceito de "qualidade de vida" - o foco do conceito passou a ser a cidade, ou seja, a qualidade de vida que a cidade oferece aos seus cidadãos. Nesse contexto, a construção de indicadores para mensurar a qualidade de vida urbana passou a revestir-se de grande complexidade, uma vez que ao longo desse período, conceitos como "pobreza", "exclusão social" e "sustentabilidade", dentre outros, entraram para a agenda política internacional e passaram a influir na formulação dos indicadores de qualidade de vida urbana (NAHAS, 2015:16).

Conclui-se que a avaliação dos índices de qualidade de vida urbana como instrumentos para políticas púbicas que visem reverter a tendência de cidades cada menos inclusivas deve, por conseguinte, atentar para a mobilidade e a acessibilidade como aspectos imbricados com a questão da qualidade de vida urbana. Ainda que as políticas de mobilidade urbana sejam essenciais para a redução da exclusão social e para a ampliação do direito à cidade, os investimentos públicos em geral não priorizam sua disponibilização em áreas periféricas. Às dificuldades de mobilidade soma-se a carência de acessibilidade; estas áreas são em sua maioria, desprovidas de equipamentos urbanos e distantes dos locais onde se concentram os empregos, imprimindo o conflito de classes no território. Nesse sentido, a análise dos índices de qualidade de vida urbana e dos elementos de mobilidade e acessibilidade, é fundamental para elaboração de políticas públicas que visem cidades socialmente justas.

\section{2. Índices de qualidade de vida urbana}

No presente trabalho analisam-se quatro índices de qualidade de vida/bem-estar que possuem em comum a incorporação de indicadores de mobilidade e/ou acessibilidade, utilizados como elementos chave para efeito de comparação.

\section{1. Índice de Qualidade de Vida Urbana de Belo Horizonte (IQVU-BH)}

O Índice de Qualidade de Vida Urbana de Belo Horizonte foi desenvolvido no início da década de 1990 pela Prefeitura de Belo Horizonte (PBH) e a Pontifícia Universidade Católica de Minas Gerais (PUC-MG) utilizando o método Delphi ${ }^{2}$ e abordagem objetiva, a qual emprega indicadores que avaliam características do ambiente

2 Os usuários foram submetidos ao processo de consultas anônimas e por escrito, até que se formasse opinião majoritária acerca dos temas a serem considerados, definidos em reunião geral ao final do processo (NAHAS, 2002). 


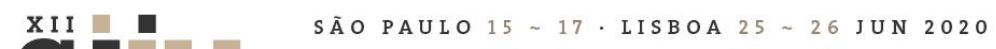

urbano por meio de dados secundários. O índice foi calculado para 81 Unidades de Planejamento (UP) distribuídas pelo município com o objetivo de fundamentar uma distribuição mais equitativa de recursos pelo Orçamento Participativo. O resultado desse processo é a mensuração do IQVU-BH para todas as UPs valores de 0 a 1 - onde, quanto maior o índice, melhor a oferta e acesso a serviços naquela unidade. Os indicadores propostos identificados na Tabela 1 foram definidos em reuniões realizadas com gestores das secretarias municipais pertinentes (NAHAS, 2002). 


\section{SÃO PAULO 15 $\quad 17$ LISBOA $25 \sim 26$ JUN 2020 \\ Seminário Internacional de \\ Seminario Internacional de Investigação em Urbanismo

\begin{tabular}{|c|c|c|c|c|}
\hline № & Variáveis/pesos & Componentes & Indicador & Fonte de Dados \\
\hline \multirow{3}{*}{1} & \multirow{3}{*}{$\begin{array}{l}\text { ABASTECIMENTO } \\
\text { ALIMENTAR } \\
(0,08)^{*}\end{array}$} & \multirow{3}{*}{$\begin{array}{l}\text { Equipamentos de } \\
\text { abastecimento } \\
\text { alimentar }\end{array}$} & m2 de hiper e supermercados/1000 hab & $\begin{array}{l}\text { Cadastro do Imposto Sobre } \\
\text { Serviços (ISS) }\end{array}$ \\
\hline & & & m2 de mercearias e similares/1000 hab & ISS \\
\hline & & & $\mathrm{m} 2$ de restaurantes e similares $/ 1000$ hab & ISS \\
\hline \multirow{4}{*}{2} & \multirow{4}{*}{$\begin{array}{c}\text { CULTURA } \\
(0,03)\end{array}$} & Patromônio Cultural & $\mathrm{n}$ - de bens tombados & $\begin{array}{l}\text { Secretaria Municipal de } \\
\text { Cultura (SMC) }\end{array}$ \\
\hline & & \multirow{2}{*}{$\begin{array}{l}\text { Equipamentos } \\
\text { culturais }\end{array}$} & no de equipamentos culturais/1000 hab & SMC \\
\hline & & & $\mathrm{m} 2$ de livrarias e papelarias/1000 hab & ISS \\
\hline & & $\begin{array}{c}\text { Programações } \\
\text { artístico-culturais }\end{array}$ & no de atividades culturais/1000 hab & SMC \\
\hline \multirow{5}{*}{3} & \multirow{5}{*}{$\begin{array}{l}\text { EDUCAÇÃO } \\
(0,13)\end{array}$} & \multirow[t]{2}{*}{ Ensino Fundamental } & $\%$ alunos matriculados E. Fundamental & $\begin{array}{l}\text { Secretaria Municipal de } \\
\text { Educação (SMED) }\end{array}$ \\
\hline & & & № alunos por turma E. Fundamental & SMED \\
\hline & & \multirow{3}{*}{ Ensino Médio } & $\%$ alunos matriculados E. Médio & SMED \\
\hline & & & № alunos por turma E. Médio & SMED \\
\hline & & & \% de aprovações final E. Médio & SMED \\
\hline \multirow{2}{*}{4} & \multirow{2}{*}{$\begin{array}{c}\text { HABITAÇÃO } \\
(0,18)\end{array}$} & \multirow{2}{*}{$\begin{array}{l}\text { Qualidade da } \\
\text { Habitação }\end{array}$} & m2 de área residencial/habitante & \begin{tabular}{|l|} 
Cadastro do Imposto Predial \\
e Territorial Urbano (IPTU)
\end{tabular} \\
\hline & & & Nota padrão acabamento das moradias & IPTU \\
\hline \multirow{8}{*}{5} & \multirow{8}{*}{$\begin{array}{c}\text { INFRAESTRUTURA } \\
\text { URBANA } \\
(0,16)\end{array}$} & \multirow{3}{*}{ Saneamento } & $\%$ da UP com rede de água & \begin{tabular}{|l} 
IPTU e Companhia \\
Urbanizadora de Belo \\
Horizonte (URBEL) \\
\end{tabular} \\
\hline & & & $\%$ da UP com rede de esgoto & IPTU e URBEL \\
\hline & & & $\%$ da UP com fornecimento contínuo de água & $\begin{array}{l}\text { Companhia de Saneamento } \\
\text { de Minas Gerais }\end{array}$ \\
\hline & & \multirow{2}{*}{ Energia Elétrica } & $\%$ da UP com rede elétrica & IPTU E URBEL \\
\hline & & & $\%$ da UP com iluminação pública & IPTU e URBEL \\
\hline & & Telefonia & $\%$ da UP com rede telefônica & IPTU e URBEL \\
\hline & & \multirow[t]{2}{*}{ Transporte Coletivo } & № de veículos/1000 hab & \begin{tabular}{|l|} 
Empresa de Transportes e \\
Trânsito de BH (BHTRANS) \\
\end{tabular} \\
\hline & & & Idade média da frota de veículos & BHTRANS \\
\hline 6 & $\begin{array}{c}\text { MEIO AMBIENTE } \\
(0,06)\end{array}$ & Conforto Acústico & Ocorrênia de ruídos/1000 hab & $\begin{array}{l}\text { Polícia Militar de Minas } \\
\text { Gerais (PMMG) }\end{array}$ \\
\hline \multirow{4}{*}{7} & \multirow{4}{*}{$\begin{array}{l}\text { SAÚDE } \\
(0,14)\end{array}$} & \multirow{4}{*}{ Atenção à Saúde } & № leitos hospitalares/1000 hab & $\begin{array}{l}\text { Secretaria Municipal de } \\
\text { Saúde (SMS) }\end{array}$ \\
\hline & & & № Postos de Saúde/1000 hab & SMS \\
\hline & & & № de outros equipamentos de Assistência Méc & iss \\
\hline & & & M2 equipamentos odontológicos/1000 hab & ISS \\
\hline \multirow{4}{*}{8} & \multirow{4}{*}{$\begin{array}{c}\text { SERVIÇOS } \\
\text { URBANOS } \\
(0,11)\end{array}$} & \multirow{2}{*}{ Serviços Pessoais } & № de agências bancárias/1000 hab & Sindicato Bancários \\
\hline & & & № de pontos de táxi/1000 hab & BHTRANS \\
\hline & & Serviços de & № de bancas de revistas/1000 hab & $\begin{array}{l}\text { Administrações Regionais da } \\
\text { PBH }\end{array}$ \\
\hline & & & № de telefones públicos/1000 hab & Telemar Norte Leste \\
\hline & & & № de equipamentos policiais/1000 hab & PMMG \\
\hline & & Atendimento Policia & № de recursos humanos da PMMG/1000 hab & PMMG \\
\hline & & & № de viaturas policiais/1000 hab & PMMG \\
\hline & & & Tempo médio de espera atendimento PMMG & PMMG \\
\hline & & & № de homicídios/1000 hab & PMMG \\
\hline & SEGURANCA & & № de tentativas de homicídios/1000 hab & PMMG \\
\hline 9 & URBANA & Seguranca Pescoal & № de violações de domicílios/1000 hab & PMMG \\
\hline & $(0,08)$ & & № de estupros/1000 hab & PMMG \\
\hline & & & № de diversas ocorrências criminais/1000 hab & PMMG \\
\hline & & & № de roubos a pessoas/1000 hab & PMMG \\
\hline & & Segurança & № de roubos e furtos de veículos $/ 1000$ hab & PMMG \\
\hline & & Patrimonial & № de roubos e furtos a imóveis/1000 hab & PMMG \\
\hline & & $\begin{array}{l}\text { Segurança no } \\
\text { Trânsito }\end{array}$ & № de acidentes com ou sem vítimas/1000 hab & PMMG \\
\hline
\end{tabular}

* Os números entre parênteses correspondem aos pesos das Variáveis no cálculo do índice.

Tabela 1 - Índice de Qualidade de Vida Urbana de Belo Horizonte (1994, 1996 e 2000). Fonte: (Nahas, 2005:113). 


\section{SÃO PAULO15 17 LISBOA $25 \sim 26$ JUN 2020}

O IQVU incorpora, na variável Infraestrutura Urbana, o componente Transporte Coletivo por meio da quantificação do número de veículos/1000 habitantes e idade média da frota, indicando a oferta de equipamentos de transporte e a qualidade dos veículos. Em relação ao peso do Transporte Coletivo no cálculo, a Prefeitura de Belo Horizonte (2016) destaca que a metodologia do IQVU transforma os componentes em variáveis por meio de uma média aritmética simples. Assim, o Transporte Coletivo é ponderado no valor de 0,04. Conclui-se, portanto, que o Transporte Coletivo foi considerado mais relevante do que os componentes vinculados às variáveis Cultura e Segurança Urbana, de mesma relevância que Saneamento, Energia Elétrica e Telefonia e menos primordial do que os componentes do Abastecimento Alimentar, Educação, Habitação, Meio Ambiente, Saúde e Serviços Urbanos.

Para além de indicadores de mobilidade, Nahas (2002:50), coordenadora do IQVU-BH, também introduziu uma medida de acessibilidade a fim de "[...] 'corrigir' os valores da oferta dos bens pela intensidade com que os mesmos são utilizados pela população local e residente em outros lugares da cidade". Por meio dessa medida, as Unidades de Planejamento passam a ser "cedentes" ou "receptoras" dos serviços urbanos, de acordo com o tipo de serviço e a sua disponibilidade em cada região.

A introdução desta medida se justifica porque, como se sabe, a população de um determinado lugar faz uso de serviços e equipamentos urbanos também fora do seu local de moradia, particularmente nas regiões onde há concentração de ofertas, como é o caso do centro e hipercentro das grandes cidades (NAHAS, 2002:50).

Houve, portanto, o cuidado de não congelar as UPs em parcelas de territórios que não se interagem. O caráter intra-urbano do IQVU se aprimora com a medida de acessibilidade que incorpora a característica dinâmica da cidade. Para o cálculo da medida de acessibilidade:

Utilizou-se a distância urbana a partir de pontos fixos (centroides), válidos para todos os serviços, que representam as zonas de maior conglomerado de serviços em cada unidade espacial. Para tanto, a BHTRANS desenvolveu um sistema que produziu uma matriz de tempos de deslocamento inter-UP, considerando não somente o tempo efetivo de deslocamento, como também o tempo de espera e os horários de pico, quando ocorrem os engarrafamentos. (NAHAS, 2002:95)

Além disso, Nahas (2000:474) relata que houve um cuidado da equipe em analisar diferentes níveis de acessibilidade onde água e esgoto, por exemplo, devem ser ofertados na própria moradia; um supermercado pode estar mais distante e um centro cultural, mais ainda. Dessa forma, as variáveis do IQVU foram classificadas em 4 categorias de acessibilidade: imediata, próxima, média e distante. A variável Infraestrutura Urbana, a qual incorpora o Transporte Coletivo como citado previamente, foi classificada como acessibilidade imediata. Assim, o IQVU tem como premissa o fato de que o transporte coletivo deve ser ofertado o mais próximo possível da residência do cidadão. 


\section{SÃOPAULO15 17 LISBOA $25 \sim 26$ JUN 2020}

Seminário Internacional de Investigação em Urbanismo

\section{2.}

\section{Índice de Qualidade de Vida de Curitiba (IQVC)}

No caso de Curitiba, o Instituto de Pesquisa e Planejamento Urbano de Curitiba (Ippuc) mensurou a qualidade de vida para os anos de 1996 e 2000 utilizando o método genebrino ou distancial ${ }^{3}$ e abordagem subjetiva emprega indicadores que avaliam características do ambiente urbano utilizando dados primários. $\mathrm{O}$ IQVC incorpora a habitação, saúde, educação e transporte (Tabela 2) e os resultados possibilitam uma análise geral do crescimento social da cidade.

O IQVC é um índice intra-urbano apresentado para cada um dos 75 bairros curitibanos, fator essencial para subsidiar as políticas urbanas municipais. Ainda, este é representado por um percentual de 0 a $100 \%$, no qual $100 \%$ é considerado o desenvolvimento ótimo. Este índice atingiu 64,59\% de satisfação em 1996 e 77,23\% em 2000 (MACHADO, 2004).

\begin{tabular}{|c|c|c|}
\hline № & Variável & Indicador \\
\hline \multirow{3}{*}{1} & \multirow{3}{*}{ HABITAÇÃO } & Domicílios em aglomerados subnormais \\
\hline & & Pessoas por domicílio \\
\hline & & Domicílios com coleta de lixo \\
\hline \multirow{7}{*}{2} & \multirow{7}{*}{ SAÚDE } & Mortalidade infantil \\
\hline & & Baixo peso ao nascer \\
\hline & & Mortalidade geral padronizada \\
\hline & & Esperança de vida ao nascer \\
\hline & & Incidência de tuberculose \\
\hline & & Incidência de AIDS \\
\hline & & Mortalidade $<$ de 5 anos \\
\hline \multirow{4}{*}{3} & \multirow{4}{*}{ EDUCAÇÃO } & Taxa de reprovação \\
\hline & & Taxa de abandono \\
\hline & & Taxa de sucesso \\
\hline & & Distorção idade/série \\
\hline \multirow{3}{*}{4} & \multirow{3}{*}{ TRANSPORTE } & Frequência \\
\hline & & Acesso à rede integrada de transporte \\
\hline & & Cumprimento de viagens \\
\hline
\end{tabular}

Tabela 2 - Índice de Qualidade de Vida Urbana de Curitiba (1996 e 2000). Fonte: (Machado, 2004).

A variável transporte inclui três indicadores: Frequência, Acesso à rede integrada de transporte - RIT - e Cumprimento de viagens, conforme indica Tabela 2. Segundo o engenheiro Machado (2004), o indicador Acesso à RIT foi calculado a partir das médias dos bairros de Curitiba, enquanto a Frequência foi mensurada por especialistas em transporte e o Cumprimento de Viagens foi quantificado por meio de uma comparação com as médias de outras capitais brasileiras.

Machado (2004) expõe que, para o ano de 1996 "o setor de transporte é o que mais se destaca, alcançando um índice de 67,34\%, seguido dos 10 setores de saúde com 64,62\%, habitação com 63,38\% e educação,

${ }^{3}$ Aceita-se como nível de vida da população (Y), em uma dada unidade de tempo ( $\mathrm{t}$ ) e em uma dada unidade de espaço $(\mathrm{d}=1,2,3 \ldots)$, o grau de satisfação das necessidades materiais e culturais das economias domésticas, obtido através dos fluxos de mercadorias e de serviços pagos (trabalho - renda) e dos fluxos do fundo de consumo coletivo (Sliwiany, 1997). 


\section{SÃO PAULO15 17 LISBOA $25 \sim 26$ JUN 2020}

com índice de $63,19 \%$ ". O cenário se altera no índice de qualidade de vida em 2000: "o setor Habitação chega a um índice de $81,74 \%$, seguido pelo setor Saúde com 79,57\%, Educação com $77,17 \%$ e Transporte com 71,27\%". O IQVC de 2000 traz o indicador de Acesso à RIT como o mais crítico dentre os indicadores de transporte, com o nível de satisfação de $49,50 \%$.

\subsection{I Índice de Qualidade de Vida de Santo André (IQVSA)}

O Índice de Qualidade de Vida de Santo André (IQVSA), ao contrário dos dois primeiros índices detalhados no presente trabalho, não se refere à qualidade de vida urbana. Contudo, a dimensão trânsito também é incorporada em seu cálculo. Esse índice emergiu de pesquisa do Datafolha aplicada de dois em dois meses, por sete vezes, na cidade de São Paulo entre os anos de 1999 e 2000.

Analisando esta série histórica, percebeu-se que existem preocupações que afligem a população e que a mesma, considerava mais importante para determinar a sua qualidade de vida. Percebeu-se que algumas preocupações são sazonais e outras adquiriram uma constância. A partir desta constatação, construiu-se indicadores para compreender a percepção da população em relação a sua qualidade de vida, tentando, na medida do possível, superar os aspectos sazonais (KEINERT ET AL, 2004).

Assim, a série histórica de São Paulo foi instrumento para a seleção de dez fatores - Poder Aquisitivo, Educação, Lazer, Moradia, Qualidade do Ar, Saúde, Segurança, Trabalho, Trânsito, Qualidade dos Serviços mais relevantes para a qualidade de vida do cidadão. Posteriormente, a equipe de Santo André elaborou quarenta perguntas relacionadas a estes dez fatores e aplicou uma pesquisa de percepção no município em junho de 2003 (KEINERT ET AL, 2004).

$\mathrm{Na}$ análise dos dados foram atribuídos escores, de 0 (categorias no extremo negativo) a 1 (categorias no extremo positivo) às respostas dos entrevistados em cada um dos tópicos acima listados. O índice obtido em cada um dos dez aspectos é resultado das médias simples dos escores correspondentes às perguntas que os compõem (KEINERT ET AL, 2004).

O IQVSA de 2003 equivale a 0,57, fato que o qualifica como insatisfatório uma vez resultados satisfatórios devem atingir, no mínimo, 0,66. Dentre os elementos pesquisados, o que recebeu a pior avaliação da população foi o lazer $(0,30)$, junto com a qualidade do ar $(0.35)$, sendo que o poder aquisitivo, foi avaliado em $(0,49)$, reduzindo a média de qualidade de vida do morador de Santo André. Ainda, ficaram abaixo da média as condições de habitação e moradia $(0,62)$, educação $(0,60)$ e trabalho $(0,57)$. Finalmente, na ponta oposta aparecem os indicadores de serviços de saúde e trânsito $(0,86)$, serviços básicos de saneamento e infraestrutura $(0,82)$ e segurança $(0,75)$ (KEINERT ET AL, 2004).

O IQVSA incorpora o fator trânsito como correlato à qualidade de vida do cidadão e o define como "o tempo que o entrevistado leva para se locomover na cidade e o grau de influência desse fator em sua rotina" (Keinert et al, 2004). Para o engenheiro e sociólogo Vasconcellos (2017), o trânsito é um conjunto de todos os deslocamentos diários, feitos pelas calçadas e vias da cidade, e que aparece na rua na forma da movimentação geral de pedestres e veículos. Adicionalmente, Araújo et al (2011) complementam que a realização da função social do trânsito passa pelo atendimento às demandas dos seus participantes por acessibilidade, mobilidade e qualidade de vida. $O$ trânsito não se refere apenas ao tempo de deslocamento 


\section{SÃOPAULO15 17 LISBOA $25 \sim 26$ JUN 2020 \\ Seminário Internacional de Investigação em Urbanismo \\ Seminario Internacional de Investigación en Urbanismo}

como incorporado no IQVSA, mas também a diversos outros elementos na qualidade da locomoção dos cidadãos.

Keinert et al (2004) destacam a contradição da percepção da população em Santo André no que tange a variável trânsito pois, apesar desta ter sido considerada a mais satisfatória, juntamente com a saúde, grande parte dos cidadãos entrevistados relatam perder tempo considerável nos deslocamentos. Os autores discorrem sobre a possibilidade de que as pessoas tenham incorporado o tempo excessivo de deslocamento em seu cotidiano, alterando a percepção sobre tal aspecto. Keinert et al (2004) ressaltam que um dos resultados da pesquisa foi o fato de que as pessoas que mais perdem tempo no trânsito são pertencentes às classes A e B (com renda familiar superior a 10 salários mínimos e com nível superior de escolaridade). Tal conclusão representa a ineficiência do trânsito em Santo André como elemento que assegure função social da cidade.

\begin{tabular}{|c|l|c|l|}
\hline No & \multicolumn{1}{|c|}{ Dimensões } & Peso & \multicolumn{1}{|c|}{ Caracterização } \\
\hline 1 & $\begin{array}{l}\text { Serviços básicos de saneamento e } \\
\text { infraestrutura }\end{array}$ & 0,82 & $\begin{array}{l}\text { Ocorrência de interrupções ou problemas com o fornecimento de } \\
\text { água e energia }\end{array}$ \\
\hline 2 & Condições de habitação e moradia & 0,62 & $\begin{array}{l}\text { Avaliação e grau de satisfação do entrevistado em relação às suas } \\
\text { atuais condições de moradia }\end{array}$ \\
\hline 3 & Trânsito & 0,86 & $\begin{array}{l}\text { Tempo que o entrevistado levou para se locomover na cidade e o } \\
\text { grau de influência desse fator em sua rotina }\end{array}$ \\
\hline 4 & Serviços de Saúde & 0,86 & $\begin{array}{l}\text { Acesso a serviços públicos e particulares de saúde e avaliação do } \\
\text { atendimento }\end{array}$ \\
\hline 6 & Erabalho & 0,57 & $\begin{array}{l}\text { Características da ocupação do entrevistado e seu grau de satisfação } \\
\text { com a função que exerce }\end{array}$ \\
\hline 7 & Segurança & 0,6 & $\begin{array}{l}\text { Grau de escolaridade do entrevistado, acesso de seus filhos à escola e } \\
\text { grau de importância que atribui ao estudo }\end{array}$ \\
\hline 8 & Poder Aquisitivo & 0,75 & $\begin{array}{l}\text { Ocorrências de roubos e agressões físicas, variação das taxas de } \\
\text { homicídio e grau de percepção do medo em relação à violência }\end{array}$ \\
\hline 9 & Qualidade do Ar & 0,49 & $\begin{array}{l}\text { Avaliação pessoal do poder aquisitivo da família e grau de } \\
\text { comprometimento da renda individual }\end{array}$ \\
\hline 10 & Lazer & 0,35 & Avaliação pessoal da qualidade do ar na cidade \\
\hline
\end{tabular}

Tabela 3 - Índice de Qualidade de Vida Urbana de Santo André (2003). Fonte: (Keinert et al, 2004).

\section{4. Índice de Bem-Estar Urbano (IBEU)}

O Índice de Bem-Estar Urbano (IBEU), apresentado pelo Observatório das Metrópoles em 2013, sintetiza o bem-estar urbano para as principais regiões metropolitanas do Brasil - Belém, Belo Horizonte, Campinas, Curitiba, Florianópolis, Fortaleza, Goiânia, Grande Vitória, Manaus, Porto Alegre, Recife, RIDE-DF, Rio de Janeiro, Salvador e São Paulo. Para Ribeiro et al (2013), representantes do Observatório das Metrópoles, o bem-estar urbano é a "compreensão daquilo que a cidade deve propiciar às pessoas em termos de condições materiais de vida, a serem providas e utilizadas de forma coletiva", conceito próximo ao de qualidade de vida urbana, fato que justifica a sua inclusão no presente artigo.

Para atingir o objetivo proposto, o IBEU foi concebido em dois tipos: Global e Local. O IBEU Global é calculado para o conjunto das 15 metrópoles do país, o que 


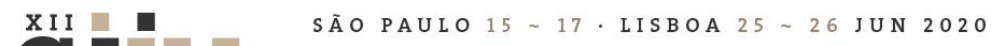
metrópoles, os municípios metropolitanos e entre bairros ${ }^{4}$ que integram o conjunto das metrópoles. O IBEU Local é calculado especificamente para cada metrópole, permitindo avaliar as condições de vida urbana interna a cada uma delas (RIBEIRO ET AL, 2013).

Segundo Ribeiro et al (2013), foram analisadas cinco dimensões: mobilidade urbana; condições ambientais urbanas; condições habitacionais urbanas; atendimento de serviços coletivos urbanos; infraestrutura urbana. Cada dimensão é composta por um conjunto de indicadores, como ilustrado na Tabela 4 a seguir, construídos a partir do censo demográfico do Instituto Brasileiro de Geografia e Estatística (IBGE) de 2010.

\footnotetext{
${ }^{4} \mathrm{~A}$ designação de bairro corresponde, neste estudo, ao que é denominado, pelo IBGE, de área de ponderação. A área de ponderação se constitui de um conjunto de setores censitários - a menor unidade territorial de coleta de dados durante a realização do censo demográfico - e se caracteriza por apresentar relativa homogeneidade demográfica e social; sempre que possível continuidade espacial; e, contiguidade municipal, ou seja, não ultrapassa o limite administrativo do município.
} 



\section{SÃO PAULO15 17 LISBOA $25 \sim 26$ JUN 2020 \\ Seminário Internacional de Investigação em Urbanismo \\ Seminario Internacional de Investigación en Urbanismo}

\section{Considerações finais}

Diante do exposto, os resultados apresentados foram sintetizados em um quadro comparativo (Tabela 5) entre os quatro índices analisados.

\begin{tabular}{|c|c|c|c|c|}
\hline & IQVU-BH & IQVC & IQVSA & IBEU \\
\hline $\begin{array}{l}\text { Finalidade da } \\
\text { elaboração/aplicação do índice }\end{array}$ & $\begin{array}{l}\text { Destino de recursos do } \\
\text { Orçamento participativo }\end{array}$ & $\begin{array}{c}\text { Elaboração de políticas } \\
\text { urbanas }\end{array}$ & $\begin{array}{c}\text { Compreender a percepção } \\
\text { da população em relação a } \\
\text { sua qualidade de vida }\end{array}$ & $\begin{array}{l}\text { Difusão da produção do } \\
\text { conhecimento e } \\
\text { informações para } \\
\text { governos, universidades, } \\
\text { movimentos sociais, } \\
\text { veículos de comunicação } \\
\text { e sociedade civil }\end{array}$ \\
\hline Abrangência territorial do índice & $\begin{array}{l}\text { Intra-urbano: Unidade de } \\
\text { Planejamento }\end{array}$ & Intra-urbano: bairro & cidade & \begin{tabular}{|} 
metrópoles, os \\
municípios \\
metropolitanos e entre \\
bairros que integram o \\
conjunto das metrópoles
\end{tabular} \\
\hline $\begin{array}{l}\text { Como se compreende a qualidade } \\
\text { de vida }\end{array}$ & $\begin{array}{l}\text { Qualidade de vida que os } \\
\text { atributos do espaço urbano } \\
\text { oferecem ao indivíduo }\end{array}$ & $\begin{array}{l}\text { Qualidade de vida do } \\
\text { indivíduo na cidade }\end{array}$ & \begin{tabular}{|c|} 
Qualidade de vida \\
individual - preocupações \\
que afligem a população
\end{tabular} & $\begin{array}{c}\text { Bem-estar que a cidade } \\
\text { deve propiciar às } \\
\text { pessoas em termos de } \\
\text { condições materiais de } \\
\text { vida, a serem providas e } \\
\text { utilizadas de forma } \\
\text { coletiva }\end{array}$ \\
\hline Abordagem & objetiva & objetiva & subjetiva & objetiva \\
\hline Variáveis consideradas & $\begin{array}{l}\text { Abastecimento alimentar, } \\
\text { cultura, educação, habitação, } \\
\text { infraestrutura urbana, meio } \\
\text { ambiente, saúde, serviços } \\
\text { urbanos e segurança urbana }\end{array}$ & $\begin{array}{c}\text { Habitação, saúde, } \\
\text { educação e transporte. }\end{array}$ & \begin{tabular}{|c|} 
Poder Aquisitivo, \\
Educação, Lazer, Moradia, \\
Qualidade do Ar, Saúde, \\
Segurança, Trabalho, \\
Trânsito, Qualidade dos \\
Serviços
\end{tabular} & $\begin{array}{c}\text { Mobilidade urbana, } \\
\text { condições ambientais } \\
\text { urbanas, condições } \\
\text { habitacionais urbanas, } \\
\text { atendimento de serviços } \\
\text { coletivos urbanos, } \\
\text { infraestrutura urbana }\end{array}$ \\
\hline $\begin{array}{l}\text { Forma como aspectos da } \\
\text { mobilidade compõem o índice }\end{array}$ & $\begin{array}{l}\text { Oferta de equipamentos de } \\
\text { transporte e a qualidade dos } \\
\text { veículos }\end{array}$ & \begin{tabular}{|c|} 
Variável transporte: \\
Frequência, Acesso à rede \\
integrada de transporte - \\
RIT - e Cumprimento de \\
viagens \\
\end{tabular} & \begin{tabular}{|c|} 
Tempo que o entrevistado \\
leva para se locomover na \\
cidade e o grau de \\
influência desse fator em \\
sua rotina \\
\end{tabular} & $\begin{array}{l}\text { Deslocamento casa- } \\
\text { trabalho }\end{array}$ \\
\hline $\begin{array}{l}\text { Forma como aspectos da } \\
\text { acessibilidade compõem o índice }\end{array}$ & $\begin{array}{c}\text { Facilidade de acesso aos } \\
\text { serviços urbanos, considerada } \\
\text { em diferentes hierarquias de } \\
\text { prioridade }\end{array}$ & $\begin{array}{l}\text { Não incorpora } \\
\text { diretamente a } \\
\text { acessibilidade }\end{array}$ & $\begin{array}{l}\text { Não incorpora } \\
\text { diretamente a } \\
\text { acessibilidade }\end{array}$ & $\begin{array}{l}\text { Não incorpora } \\
\text { diretamente a } \\
\text { acessibilidade. }\end{array}$ \\
\hline
\end{tabular}

Tabela 5 - Quadro comparativo. Fonte: elaborada pelas autoras.

No que concerne a finalidade da elaboração e aplicação dos índices elencados, todos de alguma forma foram construídos para que pudessem ser utilizados como fundamento das políticas urbanas e estudos da área. O IQVU-BH merece destaque nesse quesito por ter sido construído para se tornar critério objetivo da distribuição mais justa de recursos do orçamento municipal por meio do Orçamento Participativo.

Com relação à abrangência territorial dos índices, os índices de Belo Horizonte e Curitiba são intra-urbanos, fato que permite a construção mais precisa de políticas urbanas municipais por subdividir o território da cidade em áreas homogêneas. Por outro lado, o índice construído para Santo André é apresentado de forma condensada para toda a cidade. Já o Índice de Bem-Estar Urbano, por ter sido construído sob a ótica da metrópole, incorpora as condições de vida urbana em três escalas: entre as metrópoles, os municípios 


\section{XII $\quad$ SÃO PAULO15 17 LISBOA $25 \sim 26$ JUN 2020}

ferramenta que pode ser utilizada para políticas urbanas metropolitanas e municipais.

As diferentes abordagens - objetiva e subjetiva - integram entendimentos diferentes de qualidade de vida. Pode-se dizer que o IQVU-BH e o IBEU se aproximam por tratarem da qualidade de vida/bem-estar urbanos por meio da abordagem objetiva. Já o IQVC e IQVSA tratam da qualidade de vida individual recorrendo à abordagem subjetiva.

No que tange a mobilidade, o IQVU-BH e o IQVC consideram aspectos vinculados à rede de transporte como a oferta de equipamentos e o cumprimento de viagens, ou seja, tratam diretamente da oferta infraestrutura de transporte. No caso do índice de Santo André, a pergunta realizada aos entrevistados se relaciona ao tempo de deslocamento. Por fim, o IBEU incorpora apenas a variável deslocamento casa-trabalho desconsiderando aspectos como a qualidade, segurança dos serviços prestados e infraestrutura.

Finalmente, o único índice entre os quatro estudados que considera de fato a acessibilidade no cálculo da qualidade de vida urbana é o IQVU-BH. Este traz a medida de acessibilidade como fator inédito e essencial por compreender que o indivíduo não acessa apenas os equipamentos urbanos da Unidade de Planejamento em que reside. A possibilidade de circulação na cidade é ponto primordial para se alcançar o direito à cidade. A acessibilidade é, portanto, considerada em todas as variáveis do índice.

Portanto, a atualização dos índices de qualidade de vida é de suma importância para a avaliação das políticas urbanas existentes a fim de que os gestores públicos tenham em mãos instrumentos técnicos que permitam a ampliação das políticas inclusivas. Da mesma forma, em um cenário no qual os gastos com transporte superam os referentes à alimentação, o resultado final das avaliações de qualidade de vida é uma ferramenta que pode ser utilizada pela sociedade civil na luta pelo direito à cidade.

\section{BIBLIOGRAFIA}

ARAÚJO, M. R. M. D., OLIVEIRA, J. M. D., JESUS, M. S. D., SÁ, N. R. D., SANTOS, P. A. C. D., e LIMA, T. C. (2011). Transporte público coletivo: discutindo acessibilidade, mobilidade e qualidade de vida. Psicologia \& Sociedade, 23(3), 574-582.

ASCHER, F. (2004). Los nuevos principios del urbanismo (pp. 73-74). Madrid: Alianza.

BRASIL. Lei n. 10.257, de 10 de julho de 2001. Regulamenta os artigos 182 e 183 da Constituição Federal, estabelece diretrizes gerais da política urbana e dá outras providências. Lex: Estatuto da Cidade, Brasília, jul. 2001. Disponível em http://www.planalto.gov.br/ccivil_03/leis/leis_2001/110257.htm. Acesso em: 03/02/2020.

BRASIL. Lei $n^{0} 12.587$, de 3 de janeiro de 2012. Política Nacional de Mobilidade Urbana. Planalto. Disponívelemhttp://www.planalto.gov.br/ccivil_03/_ato2011-2014/2012/lei/12587.htm. Acesso em: 03/02/2020.

CARDOSO, C. E. P. (2008). Análise do transporte coletivo urbano sob a ótica dos riscos e carências sociais. Tese de Doutorado, Programa de Pós-graduação em Serviço Social, Pontifícia Universidade Católica de São Paulo, São Paulo, SP.

CARDOSO, L.; MATOS, R. Acessibilidade urbana e exclusão social: novas relações, velhos desafios. In: SIMPÓSIO NACIONAL DE GEOGRAFIA URBANA, 10. 2007, Florianópolis, Santa Catarina. Anais... Florianópolis: Editora UFSC, 2007.

HANSON, S. (1995). Getting there: urban transportation in context. Geography of urban transportation. 


\section{SÃO PAULO15 17 LISBOA $25 \sim 26$ JUN 2020}

INSTITUTO BRASILEIRO DE GEOGRAFIA E ESTATISTICA (IBGE). Pesquisa de Orçamentos Familiares 2017-2018: primeiros resultados. Rio de Janeiro: IBGE, 2019.

KEINERT T. M. M., KEINERT R. C., FEFFERMANN M. (2004). Pesquisa de Percepção da Qualidade de Vida Em Santo André/Sp. II Seminário Internacional de Pesquisa e Estudos Qualitativos.

LEFÈBVRE, H. (2001). O Direito à Cidade (Vol. 5). São Paulo: Centauro.

MACHADO, P. H. B. (2004). Curitiba, a qualidade e a vida. Revista Internacional Interdisciplinar INTER thesis, 1(1), 1-25.

NAHAS, M. I. P. Metodologia de construção de índices e indicadores sociais, como instrumentos balizadores da gestão municipal da qualidade de vida urbana: uma síntese da experiência de Belo Horizonte. In: Seminário sobre indicadores de sustentabilidade, 2000, UNICAMP, Migração e Ambiente nas Aglomerações Urbanas, Campinas, Núcleo de Estudos de População, 2001, p. 465 - 490.

NAHAS, M. I. P. Bases teóricas, metodologia de elaboração e aplicabilidade de indicadores intra-urbanos na gestão municipal da qualidade de vida urbana em grandes cidades: o caso de Belo Horizonte. 2002. Tese (Doutorado em Ecologia e Recursos Naturais) - Centro de Ciências Biológicas e da Saúde, Universidade Federal de São Carlos, São Paulo.

NAHAS, M. I. P. (2015). Qualidade de vida urbana: abordagens, indicadores e experiências internacionais. In Qualidade de vida urbana: abordagens, indicadores e experiências internacionais.

ORGANIZAÇÃO MUNDIAL DE SAÚDE (OMS). Cuidados inovadores para condições crônicas: componentes estruturais de ação: relatório mundial Genebra: OMS; 2002.

RIBEIRO, L. D. Q., e RIBEIRO, M. G. (2013). IBEU: índice de bem-estar urbano. Rio de Janeiro: Letra Capital, 262.

SANTOS, B. J. R. D. (2000). A qualidade no serviço de transporte público urbano. Arquivo.

SIEVERTS, T. Cities without cities: an interpretation of the Zwischenstadt. Routledge, 2003.

SLIWIANY, R.M. (1997). Sociometria: como avaliar a qualidade de vida e projetos sociais, Editora Petrópolis: Vozes.

VASCONCELLOS, E. A. (2001). Transporte urbano, espaço e eqüidade: análise das políticas públicas. Annablume.

VASCONCELLOS, E. A. (2017). O que é trânsito. Brasiliense. 